\title{
Required Specification of Residential End-use Energy Demand Model for Application to National GHG Mitigation Policy Making - Case Study for the Japanese Plan for Global Warming Countermeasures
}

\author{
Sugiyama Minami ${ }^{1}$, Taniguchi-Matsuoka Ayako ${ }^{1}$, Yamaguchi Yohei ${ }^{1}$, Shimoda Yoshiyuki ${ }^{1}$ \\ ${ }^{1}$ Osaka University, Osaka, Japan
}

\begin{abstract}
This paper discusses the required specifications of a simulation model for evaluating global warming mitigation policy. The specifications are to reproduce the process of energy consumption in actual households and to consider the diversity of households. We applied the simulation model having these specifications to the evaluation of the Japanese 2030 Plan for Global Warming Countermeasures. We confirm the $\mathrm{CO}_{2}$ reduction target in 2030 will be achieved by implementing the government's plan. However, if high-efficiency water heaters are not distributed to households suitable for their energy characteristics, the effect of installing them will be much less than the predicted benefit.
\end{abstract}

\section{Introduction}

In Japan, heating energy consumption accounts for only $24.1 \%$ of all residential energy consumption (Agency for Natural Resources and Energy, 2018), and other energy consumption accounts for a large percentage compared with Europe and North America. Therefore, measures for various kinds of end use should be taken to reduce greenhouse gas $(\mathrm{GHG})$ emissions from the Japanese residential sector.

In 2015, the Japanese government announced a new target for GHG emissions reduction as Japan's Intended Nationally Determined Contribution (INDC) under the United Nations framework for GHG reductions. The target of $\mathrm{CO}_{2}$ emissions reduction in the residential sector is $39 \%$ by 2030 from the 2013 level. In its Long-term Energy Supply and Demand Outlook, the Japanese government suggests countermeasures for the residential sector, such as energy-saving standards for newly built houses, installation of high-efficiency water heaters, and installation of high-efficiency lighting devices and appliances, as shown in Table 1. The government estimates that the target reduction can be achieved by these countermeasures. To achieve the reduction target, it is necessary to quantitatively evaluate the GHG emission reduction effected by these measures.

Quantitative evaluation of household energy demand entails two difficulties. First, it is fundamentally driven by occupants' behaviour. The effectiveness of installing high-efficiency appliances depends on their operating hours. In particular, the energy demand of hot water heaters, lighting, and other appliances, which accounts for a large percentage of household energy consumption in
Japan, strongly depends on the occupants' behaviour. Because heating and cooling equipment generally operates intermittently in Japan, the occupants' behaviour also affects heating and cooling demand. It is important to simulate the end use with a procedure that mimics actual household behaviour.

Second, the household energy consumption differs by various factors, such as climate conditions, family composition, and building specification. Thus, $\mathrm{CO}_{2}$ reduction measures are also affected by these factors. To quantitatively evaluate their effect, these factors are considered in the evaluation and their distribution at the national scale should be as accurate as possible.

This paper discusses the applicability of the bottom-up archetype simulation model developed by the authors as a global warming mitigation policy evaluation tool, to judge whether the target will be achieved by 2030 . Our model resolves the first difficulty noted above by estimating energy consumption in each representative household based on the appliance operation schedule determined by the time use schedule of every occupant in the household. In addition, the second difficulty was resolved by considering 42,864 household categories that consist of 19 family compositions, 12 building categories (6 categories for detached houses and 6 categories for apartments, depending on the floor area), 4 building insulation levels (no insulation, 1980 standard, 1992 standard, and 1999 standard), and 47 prefectures.

The methodology that is practically applied to policy making in the Japanese INDC (Agency for Natural Resources and Energy, 2015; Ministry of the Environment, 2016) is quite simple. The method estimates total effect by multiplying effect per unit in a "standard operation schedule" by the number of installations. The estimation did not consider the difference of energy demand by various factors. Therefore, it is not enough to evaluate the effect by the measures at a national scale.

Wakiyama et al. (2017) statistically forecasted household electricity demand patterns by a time-series regression model. The estimation did not consider differences in energy use among households by various factors. The model also cannot explain the breakdown of the effect obtained by combinations of several measures. A regression model of this kind cannot forecast the reduction of energy demand by extremely stringent measures. 
Sweetnam et al. (2017) estimated energy demand in the U.K. domestic stock by using a bottom-up archetype simulation model that combines occupants' behaviour and appliance operation. They assumed that energy use patterns vary by employment status and household income. However, other important factors, such as age, working status, and presence of children, were not considered.

Sousa et al. (2017) evaluated $\mathrm{CO}_{2}$ and energy reduction from U.K. housing stock under two scenarios, "perfect uptake" and "conditional uptake", by a modular platform for dynamic simulation. Ballarini et al. (2014) evaluated potential energy savings and $\mathrm{CO}_{2}$ emissions reduction of the residential building stock in the Piedmont region of Italy. A method for defining "reference buildings" for each building category is discussed. These papers focused on heating energy consumption. It is necessary to evaluate studies in colder countries to apply these methods to warmer countries like Japan.

Table 1: GHG mitigation measures for the residential sector in Japan

\begin{tabular}{|c|c|c|c|}
\hline \multicolumn{2}{|c|}{ Measure } & 2013 & 2030 \\
\hline \multicolumn{2}{|c|}{$\begin{array}{c}\text { Energy-saving standard for newly } \\
\text { built houses }\end{array}$} & \multirow[t]{2}{*}{$6 \%$} & \multirow[t]{2}{*}{$30 \%$} \\
\hline Insulation retrof & it of existing houses & & \\
\hline \multirow{3}{*}{$\begin{array}{c}\text { Installation of } \\
\text { high-efficiency } \\
\text { water heaters }\end{array}$} & $\begin{array}{c}\text { Electric heat pump } \\
\text { water heater }\end{array}$ & $4,220,000$ & $14,000,000$ \\
\hline & $\begin{array}{c}\text { Condensing gas/oil } \\
\text { water heater }\end{array}$ & $4,480,000$ & $27,000,000$ \\
\hline & $\begin{array}{c}\text { Fuel cell } \\
\text { cogeneration }\end{array}$ & 50,000 & $5,300,000$ \\
\hline \multicolumn{2}{|c|}{$\begin{array}{c}\text { Installation of high-efficiency } \\
\text { lighting devices }\end{array}$} & $9 \%$ & $100 \%$ \\
\hline \multicolumn{2}{|c|}{$\begin{array}{l}\text { Improvement of appliance energy } \\
\text { efficiency by the Japanese top- } \\
\text { runner standard }\end{array}$} & \multicolumn{2}{|c|}{ Different by appliances } \\
\hline
\end{tabular}

\section{Simulation model}

Figure 1 shows the outline of the simulation model. This model can estimate household energy demand using a procedure that is similar to that used by actual houses because appliance operation is determined by the behaviour schedule of every occupant. In addition, the model replicates the diversity of household energy demand by considering various factors as input conditions. A household energy simulation is carried out according to the following procedure. The occupant behaviour schedule model generates a behaviour schedule for every occupant in the representative household at 5-minute intervals (Yamaguchi et al., 2014). The behaviour schedules are created using occupant attributes, including age, gender, length of working hours, and presence of children in the household. Appliance operation is determined stochastically from the occupant behaviour and the frequency of appliance use. The model then estimates the appliance energy consumption using the specifications for each appliance.

The energy demand for hot water use is calculated from the amount of hot water needed for each activity, the hot water temperature, the city water temperature estimated from the outside air temperature, and the energy efficiency and operating pattern of each water heater type.

The heat load for space heating and cooling is calculated by dynamic heat load calculation using the thermal circuit network method (Shimoda et al., 2007). The heating and cooling energy-use model determines the heating and cooling demand for each time step and room based on the weather data, building specifications, and the air temperature setting. In this calculation procedure, the internal heat gain from occupants and appliances is also considered. The heating and cooling equipment operating schedule is determined stochastically from the occupant

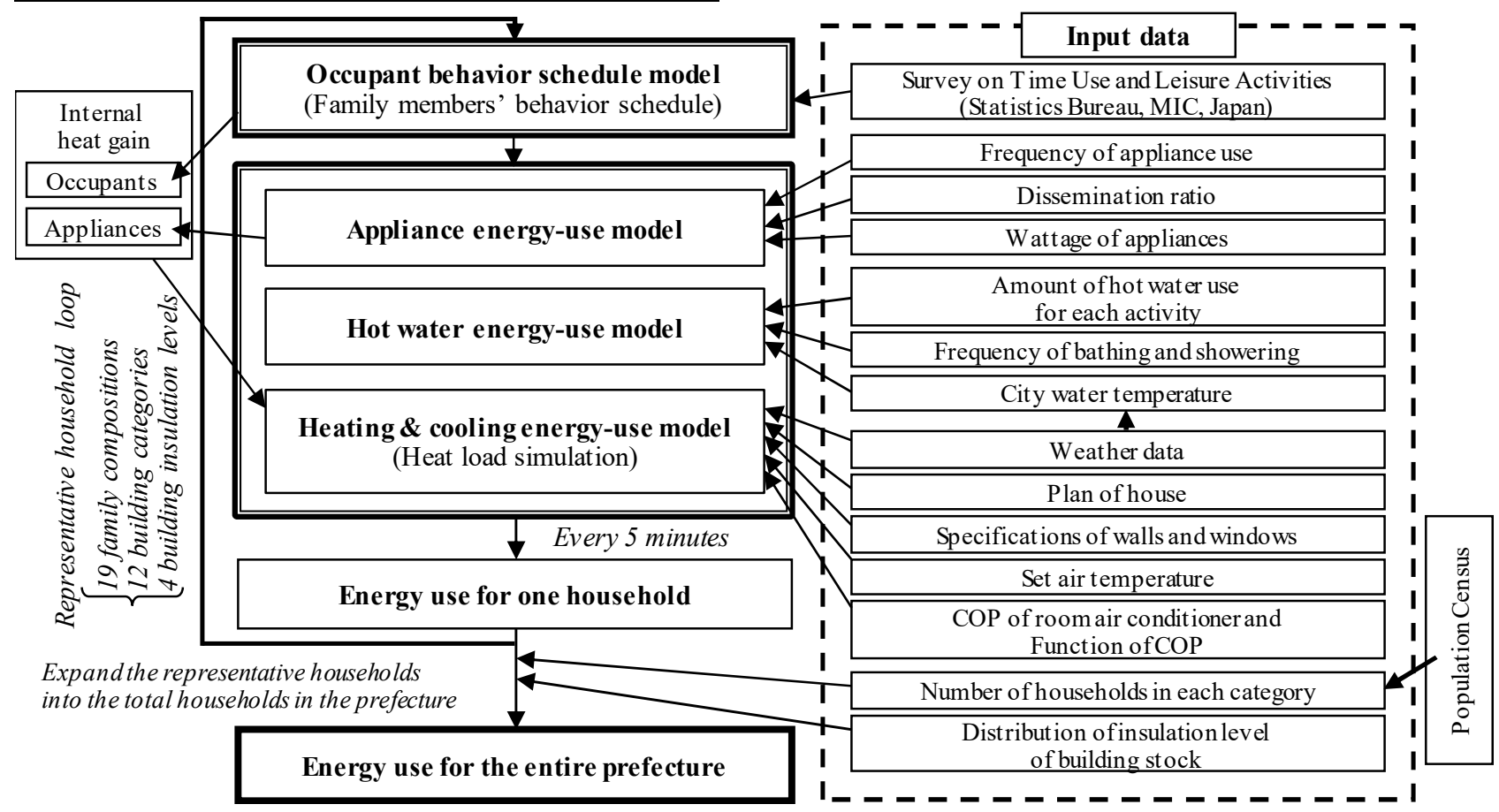

Figure 1: Outline of simulation model 
behaviour schedule and the off-to-on state transition probabilities. The coefficient of performance (COP) of room air conditioners (RACs) is determined by load factor and outdoor air temperature. We previously verified that we can retain good accuracy when we simplify the heat load calculation (Fujii et al., 2005).

The national-scale residential energy consumption is estimated by summing up the energy consumption in 47 prefectures. All of the households in the target prefecture are classified into 912 categories consisting of 19 family compositions (Table 2), 12 building categories (Table 3 ), and 4 building insulation levels. Maintaining this distribution, $0.05 \%$ of the households are chosen to represent the prefecture. The energy use simulation is carried out for each representative household according to the procedure described above. Finally, the total energy consumption in the target prefecture is estimated by extrapolating the simulation results of $0.05 \%$ of households to all of the households in the prefecture.

Table 2: Family categories

\begin{tabular}{|c|c|c|c|}
\hline No. & $\begin{array}{c}\text { Family } \\
\text { size }\end{array}$ & $\begin{array}{c}\text { Family } \\
\text { composition }\end{array}$ & $\begin{array}{c}\text { Number of } \\
\text { working persons }\end{array}$ \\
\hline 1 & \multirow{4}{*}{ Single } & Male & 1 \\
\hline 2 & & Female & 1 \\
\hline 3 & & Elderly male & 0 \\
\hline 4 & & Elderly female & 0 \\
\hline 5 & \multirow{5}{*}{2 people } & \multirow{2}{*}{ Couple } & 2 \\
\hline 6 & & & 1 \\
\hline 7 & & Elderly couple & 0 \\
\hline 8 & & Mother and 1 & 2 \\
\hline 9 & & child & 1 \\
\hline 10 & \multirow{4}{*}{3 people } & \multirow{2}{*}{$\begin{array}{l}\text { Couple and } 1 \\
\text { child }\end{array}$} & 3 \\
\hline 11 & & & 2 \\
\hline 12 & & \multirow{2}{*}{$\begin{array}{l}\text { Mother and } \\
\text { children }\end{array}$} & 1 \\
\hline 13 & & & 0 \\
\hline 14 & \multirow{2}{*}{4 people } & \multirow{2}{*}{$\begin{array}{l}\text { Couple and } \\
\text { children }\end{array}$} & 2 \\
\hline 15 & & & 1 \\
\hline 16 & \multirow{2}{*}{5 people } & \multirow{2}{*}{$\begin{array}{c}\text { Couple and } \\
\text { children }\end{array}$} & 2 \\
\hline 17 & & & 1 \\
\hline 18 & \multirow{2}{*}{$\begin{array}{l}\text { More than } \\
5 \text { people }\end{array}$} & \multirow{2}{*}{$\begin{array}{c}\text { Couple, } \\
\text { children, and } \\
\text { parents }\end{array}$} & 2 \\
\hline 19 & & & 1 \\
\hline
\end{tabular}

Table 3: Building categories

\begin{tabular}{|c|c|c|}
\hline No. & Building type & Area \\
\hline 1 & \multirow{6}{*}{ Apartment } & $<20 \mathrm{~m}^{2}$ \\
\hline 2 & & $20-40 \mathrm{~m}^{2}$ \\
\hline 3 & & $40-60 \mathrm{~m}^{2}$ \\
\hline 4 & & $60-80 \mathrm{~m}^{2}$ \\
\hline 5 & & $80-100 \mathrm{~m}^{2}$ \\
\hline 6 & & $\geq 100 \mathrm{~m}^{2}$ \\
\hline 7 & \multirow{6}{*}{ Detached house } & $<40 \mathrm{~m}^{2}$ \\
\hline 8 & & $40-60 \mathrm{~m}^{2}$ \\
\hline 9 & & $60-80 \mathrm{~m}^{2}$ \\
\hline 10 & & $80-100 \mathrm{~m}^{2}$ \\
\hline 11 & & $100-120 \mathrm{~m}^{2}$ \\
\hline 12 & & $\geq 120 \mathrm{~m}^{2}$ \\
\hline
\end{tabular}

\section{Data preparation}

This study estimated the energy consumption and $\mathrm{CO}_{2}$ emissions from the Japanese residential sector in 2013 and 2030. Table 4 shows the $\mathrm{CO}_{2}$ emission factors for these 2 years.

Table 4: $\mathrm{CO}_{2}$ emission factors

\begin{tabular}{|c|c|c|}
\hline Energy source & $\mathbf{2 0 1 3}$ & $\mathbf{2 0 3 0}$ \\
\hline Electricity $\left[\mathrm{kg} \mathrm{CO}_{2} / \mathrm{kWh}\right]$ & 0.57 & 0.37 \\
\hline $\mathrm{Gas}[\mathrm{kg} \mathrm{CO} / \mathrm{GJ}]$ & \multicolumn{3}{|c|}{53.9} \\
\hline Oil $\left[\mathrm{kg} \mathrm{CO}_{2} / \mathrm{GJ}\right]$ & \multicolumn{3}{|c|}{68.6} \\
\hline
\end{tabular}

\section{Number of households and building stock}

The number of households for each category was estimated based on the National Population Census (Statistics Bureau, 2010), population projections (National Institute of Population and Social Security Research, 2013), and building thermal insulation stock models (Taniguchi et al., 2008). Figure 2 shows the ratio of family size to all households in 2013 and 2030. Figure 3 shows the proportion of building stock complying with each insulation standard. In Japan, the level of building insulation stock is relatively low because the energy efficiency standard for residential buildings is not mandatory. The ratio in 2030 was set according to the government's plan that all houses built after 2020 must comply with the standard for building insulation.

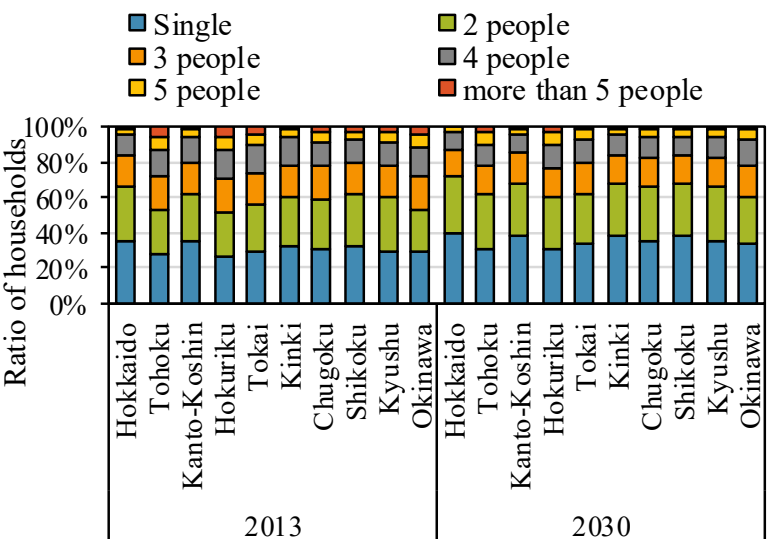

Figure 2: Ratio of family size to all households

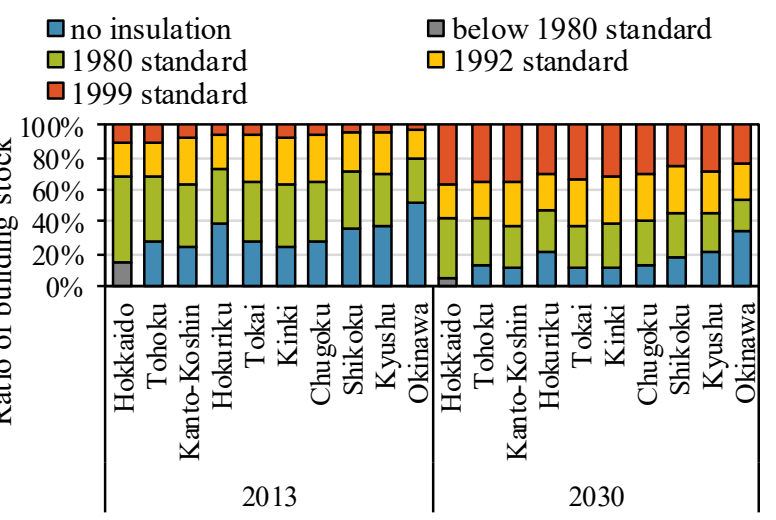

Figure 3: Ratio of building stock compliance with each insulation standard to total number of buildings

\section{Share of water heater types}

This study considers seven types of water heaters, as shown in Figure 4: electric (Elec), heat pump (HP), 
conventional gas (Conv-gas), condensing gas (Cond-gas), conventional oil (Conv-oil), condensing oil (Cond-oil), and polymer electrolyte fuel cell (PEFC). The share of water heaters by region, household size, and building type was determined from a questionnaire survey.

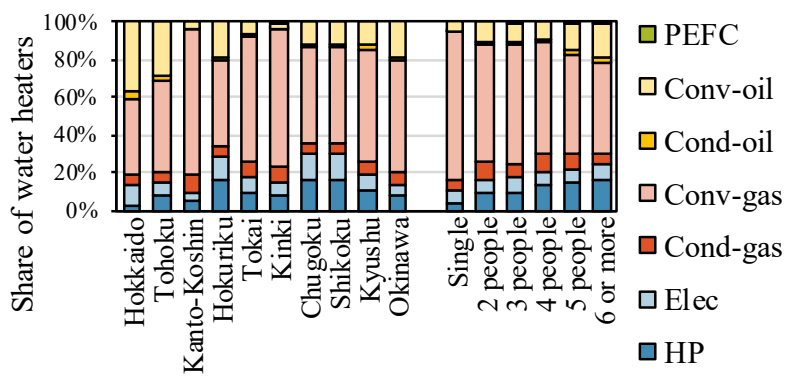

Figure 4: Share of water heaters by region and household size

\section{Simulation result for 2013 and verification}

\section{Energy consumption at national scale}

Figure 5 compares the simulation result of annual end-use energy consumption in Japan with government statistics (Agency for Natural Resources and Energy of METI, 2015). The simulated gas and oil consumption agreed well with the statistics. However, the simulated electricity consumption was lower than the statistics by $18 \%$. One reason for this difference is that the statistics include nonresidential energy consumption, such as vending machines, businesses in detached houses, and public spaces in apartment buildings. In addition, the model cannot consider households with extremely high energy consumption and appliances, such as recently introduced air cleaning machines and humidifiers that are not covered by the model.

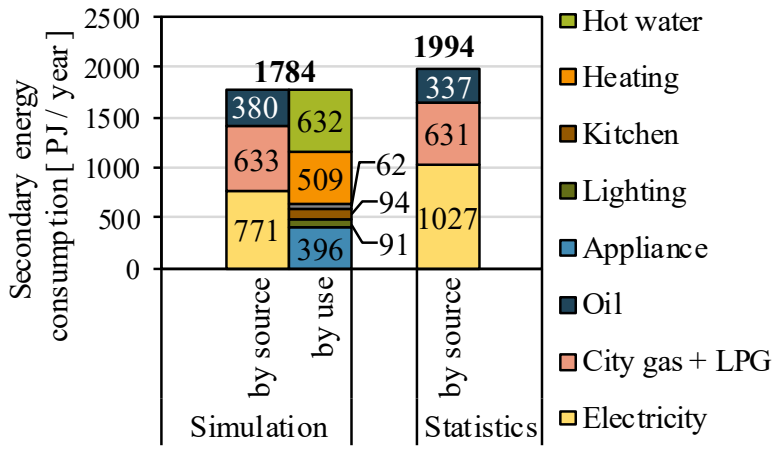

Figure 5: Secondary energy consumption in 2013

\section{Energy consumption per household}

Figure 6 compares the simulated annual energy consumption per household with government statistics (Ministry of the Environment, 2016). The simulation used weather conditions from Oct. 1, 2014 to Sep. 30, 2015, which matches the statistics' dates. The simulation can accurately reproduce the difference of energy consumption among regions, such as large oil consumption in cold regions, including Hokkaido, Tohoku, and Hokuriku.

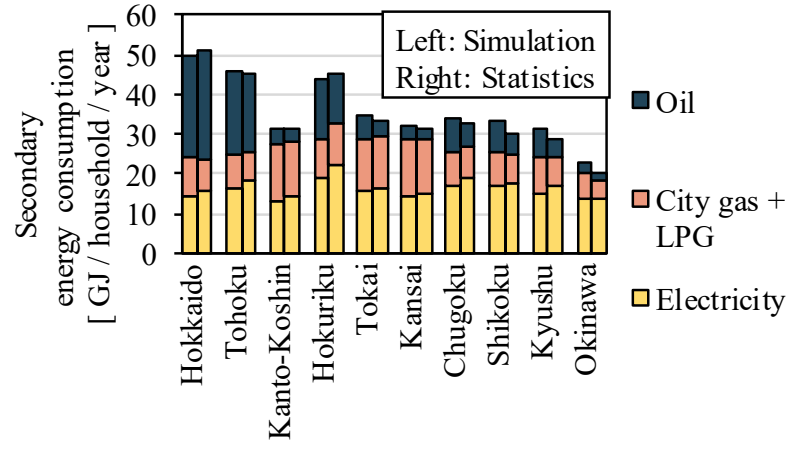

Figure 6: Secondary energy consumption per household

\section{Difference of $\mathrm{CO}_{2}$ reduction effect among households}

\section{Achievement of energy-saving standard of housing insulation}

Figure 7 shows the simulated $\mathrm{CO}_{2}$ reduction by the achievement of 1999 standards for housing insulation. In all regions, $\mathrm{CO}_{2}$ emissions decreased with increasing family size because large households generally live in large houses and have many occasions to use multiple rooms at the same time. Comparing among regions, the $\mathrm{CO}_{2}$ emissions reduction in cold regions is more than double that in other regions.

$\square$ Appliance $\square$ Lighting $\square$ Cooling $\square$ Heating $\square$ Water heater

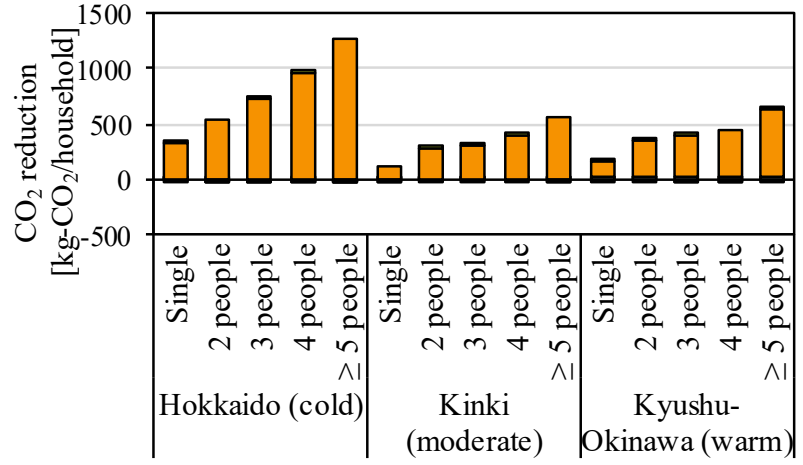

Figure 7: $\mathrm{CO}_{2}$ reduction by achievement of energysaving standard of housing insulation

Improvement of appliance energy efficiency

This study assumed that the energy efficiency of TVs, refrigerators, and RACs will improve, as shown in Table 5. Figure 8 shows the simulated $\mathrm{CO}_{2}$ reduction with improved appliance energy efficiency. The $\mathrm{CO}_{2}$ reduction due to appliances other than RACs increases with increasing family size. Regarding improvement of the rated COP of RACs, the reduction of cooling energy use in warm regions is larger than that in others. The $\mathrm{CO}_{2}$ emissions due to heating increase in cold regions. This is because improved energy efficiency decreases the internal heat generated by appliance operation. Additionally, the emissions reductions from RACs are very low because gas and oil heaters are commonly used for heating in these regions. The reduction effects due to heating are also low in the other regions because of decreases in internal heat generation. 
Table 5: Energy efficiency of TVs, refrigerators, and $R A C s$ in 2013 and 2030

\begin{tabular}{|c|c|c|c|}
\hline \multicolumn{2}{|c|}{ Appliance } & $\mathbf{2 0 1 3}$ & $\mathbf{2 0 3 0}$ \\
\hline \multicolumn{1}{|c|}{ TV power consumption [W] } & 129.9 & 81.7 \\
\hline \multirow{4}{*}{$\begin{array}{c}\text { Refrigerator power } \\
\text { consumption by volume } \\
{[\mathrm{kWh} / \text { year] }}\end{array}$} & $\leq 250 \mathrm{~L}$ & 517.2 & 429.0 \\
\cline { 2 - 4 } & $300-350 \mathrm{~L}$ & 554.2 & 430.5 \\
\cline { 2 - 4 } & $350-400 \mathrm{~L}$ & 536.1 & 432.5 \\
\cline { 2 - 4 } & $400-450 \mathrm{~L}$ & 502.4 & 333.5 \\
\cline { 2 - 4 } & $450-500 \mathrm{~L}$ & 510.8 & 280.0 \\
\cline { 2 - 4 } & $>500 \mathrm{~L}$ & 653.8 & 367.0 \\
\hline \multirow{4}{*}{$\begin{array}{c}\text { Rated COP of RACs } \\
\text { (cooling mode/ } \\
\text { heating mode) }\end{array}$} & $2.2 \mathrm{~kW}$ & $4.75 / 5.16$ & $5.79 / 6.29$ \\
\cline { 2 - 4 } & $2.5 \mathrm{~kW}$ & $4.70 / 5.21$ & $5.73 / 6.35$ \\
\cline { 2 - 4 } & $2.8 \mathrm{~kW}$ & $4.61 / 5.05$ & $5.62 / 6.15$ \\
\cline { 2 - 4 } & $3.6 \mathrm{~kW}$ & $3.76 / 4.42$ & $4.58 / 5.38$ \\
\cline { 2 - 4 } & $4.0 \mathrm{~kW}$ & $3.66 / 4.14$ & $4.46 / 5.04$ \\
\hline
\end{tabular}

$\square$ Appliance $\square$ Lighting $\square$ Cooling $\square$ Heating $\square$ Water heater

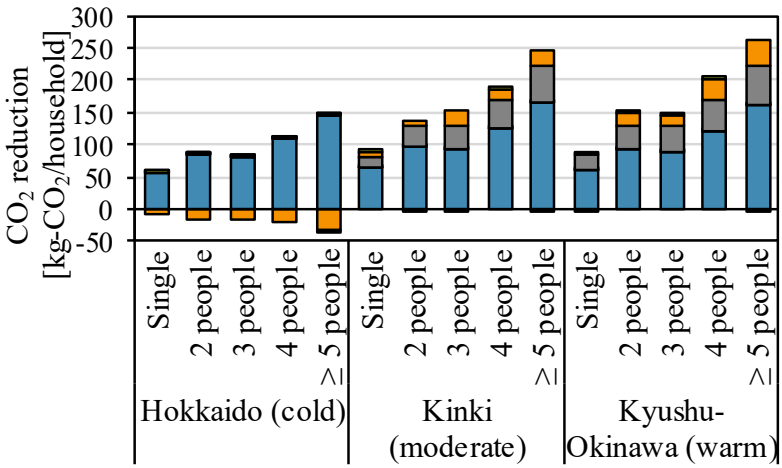

Figure 8: $\mathrm{CO}_{2}$ reduction by improvement of appliance energy efficiency

\section{Installation of high-efficiency lighting devices}

Figure 9 shows the simulated $\mathrm{CO}_{2}$ emission reduction by replacing fluorescent lamps with LEDs. The $\mathrm{CO}_{2}$ reduction increase with increasing total floor area. Heating energy use is increased by the decrease of internal heat gain from lighting device. This trend is particularly strong for cold regions.

$\square$ Appliance $\square$ Lighting $\square$ Cooling $\square$ Heating $\square$ Water heater

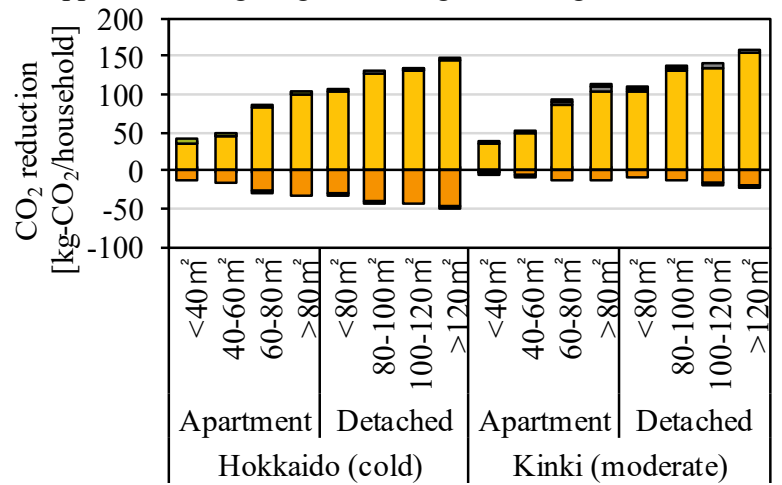

Figure 9: $\mathrm{CO}_{2}$ reduction by installation of highefficiency lighting devices

\section{Installation of high-efficiency water heaters}

Figure 10 shows the simulated $\mathrm{CO}_{2}$ reduction by replacing conventional gas water heaters with three kinds of high-efficiency water heaters. In this simulation, the $\mathrm{CO}_{2}$ emission factor of electricity was set to $0.37 \mathrm{~kg}$ $\mathrm{CO}_{2} / \mathrm{kWh}$, which is the 2030 target value. The $\mathrm{CO}_{2}$ reduction by all high-efficiency water heaters increases with increasing household size due to a larger amount of hot water demand. The $\mathrm{CO}_{2}$ reduction varies even among households with the same family size because of differences in city water temperature, operation COP depending on the outdoor temperature, hot water demand, and behaviour. The $\mathrm{CO}_{2}$ reduction by introducing HP varies widely depending on the family size compared with other high-efficiency water heaters. Regarding PEFC, the largest effect is obtained in almost all households with more than 5 people. In contrast, the $\mathrm{CO}_{2}$ emission increases in single-person households because a low load factor decreases the power generation efficiency of PEFC. In addition, $\mathrm{CO}_{2}$ reduction by PEFC is estimated to be smaller in this study because changes in the composition of power sources in the grid by increasing power generation from cogeneration systems are not considered.

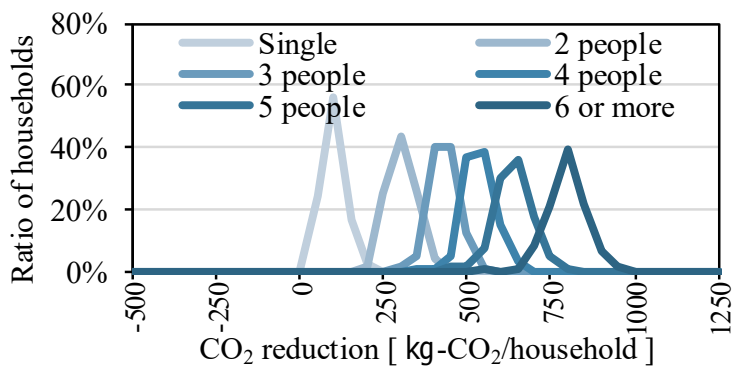

(a) $H P$

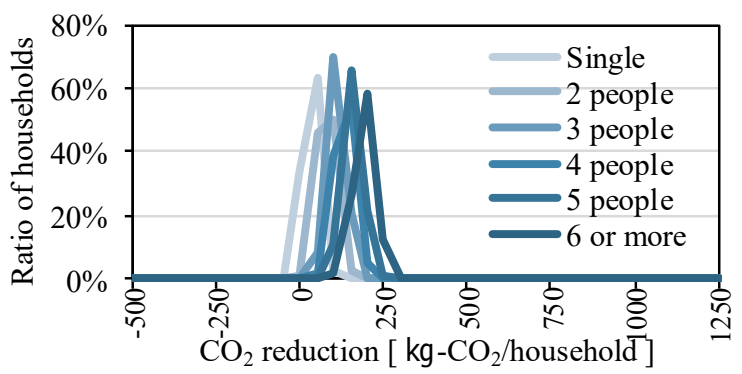

(b) Cond-gas

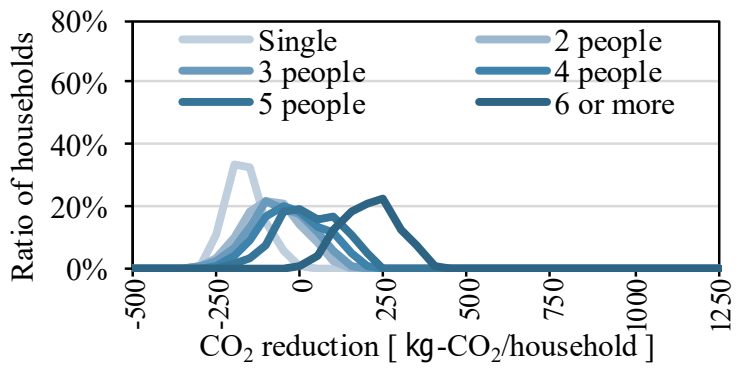

(c) $P E F C$

Figure 10: Frequency distribution of $\mathrm{CO}_{2}$ reduction

\section{$\mathrm{CO}_{2}$ reduction at national scale}

\section{Case study for 2030}

In this section, $\mathrm{CO}_{2}$ emissions in 2030 are predicted for four cases. The "business-as-usual (BAU) case" assumes that no additional energy-saving measures will be implemented. In the "countermeasure case", all measures in the Long-term Energy Supply and Demand Outlook 
(Table 1) will be implemented as planned. Because the allocation of each type of water heater to various households is not specified in this outlook, three cases were assumed in this study as follows: In case 1, the allocation of each type of water heaters is determined according to current trends of water heater installation. In cases 2 and 3, allocations were determined to maximize (case 2) and minimize (case 3) $\mathrm{CO}_{2}$ reduction at the national scale. The allocation for each case was determined according to the following four steps:

1. Conventional water heaters in 4,930,000 households, with $\mathrm{CO}_{2}$ emissions in the BAU case being the lowest (case 2) and highest (case 3), are assumed to remain.

2. PEFCs are used in 5,300,000 households, whose $\mathrm{CO}_{2}$ reduction from Cond-gas are largest (case 2) and smallest (case 3) among the remaining households.

3. HPs are used in 14,000,000 households, whose $\mathrm{CO}_{2}$ reduction from Cond-gas are largest (case 2) and smallest (case 3) among the remaining households.

4. Cond-gas and Cond-oil units are assigned to the remaining 27,000,000 households.

Figure 11 shows the shares of water heaters for all three cases.

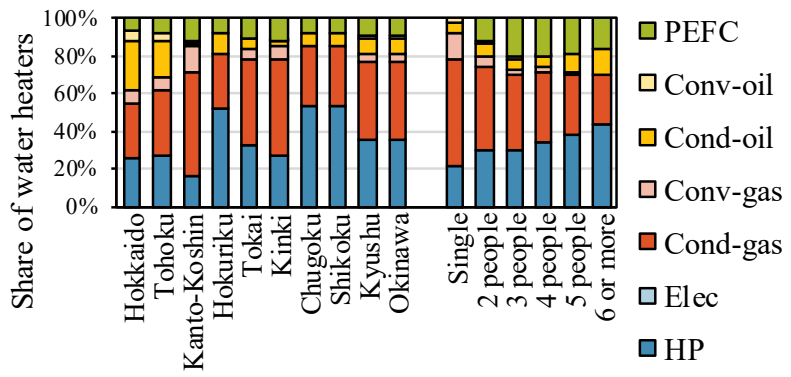

(a) Case 1-current trends

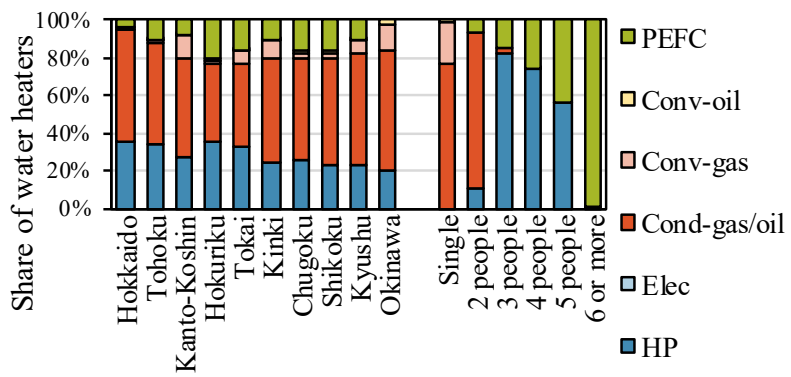

(b) Case 2-minimized $\mathrm{CO}_{2}$ reduction

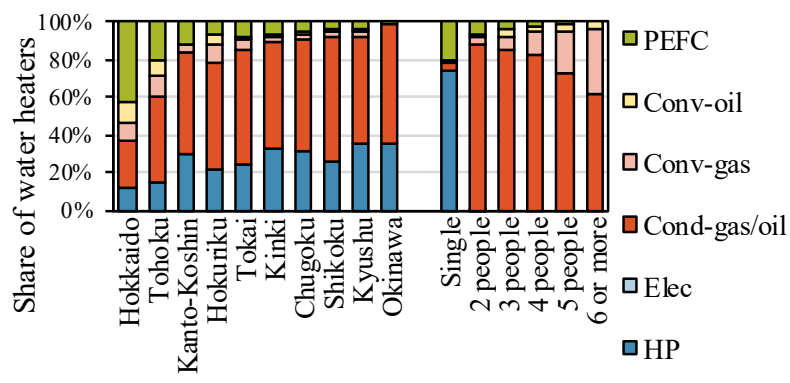

(c) Case 3-maximized $\mathrm{CO}_{2}$ reduction

Figure 11: Distribution of water heater types in 2030

\section{$\mathrm{CO}_{2}$ emission and reduction in national scale}

Figure 12 shows the simulated residential $\mathrm{CO}_{2}$ emissions in 2013, the BAU case, and case 1 . In the BAU case, the $\mathrm{CO}_{2}$ emissions decrease to $169.3 \mathrm{Mt}$. In case 1 , the $\mathrm{CO}_{2}$ emissions are $109.7 \mathrm{Mt}$, which corresponds to a $40 \%$ reduction from 2013. The result implies that we have the potential to achieve the $39 \%$ reduction target determined by the government. The reduction from the BAU case to case 1 is caused by the improvement of the $\mathrm{CO}_{2}$ emission factor $(39.7 \mathrm{Mt})$ from electricity generation and the introduction of energy-saving measures $(20.0 \mathrm{Mt})$.

Figure 13 shows the simulated $\mathrm{CO}_{2}$ reduction by each energy-saving measure from the BAU case to case 1 . The $\mathrm{CO}_{2}$ reduction achieved by implementing multiple measures simultaneously is different from the summation of that by implementing each measure individually because of the interaction among measures. For example, improvement of building insulation reduces the heating load, consequently reducing the energy-saving effect of introduction of high-efficiency RACs. Our model considers this kind of interaction, as shown in Figure 13. The simulated total reduction is less than the government's estimation. The reduction by compliance with the energy-saving standard of housing insulation is largest. The simulated reduction by installation of LEDs is approximately half of the government's estimate

- Power generation from CGS $\square$ Hot water

$\begin{array}{ll}\square \text { Heating } & \text { aCooling }\end{array}$

$\begin{array}{ll}\square \text { Kitchen } & \text { a Lighting } \\ \square \text { Appliance } & \text { a Unspecified }\end{array}$

$\square$ Oil $\quad$ व City gas + LPG

$\square$ Electricity

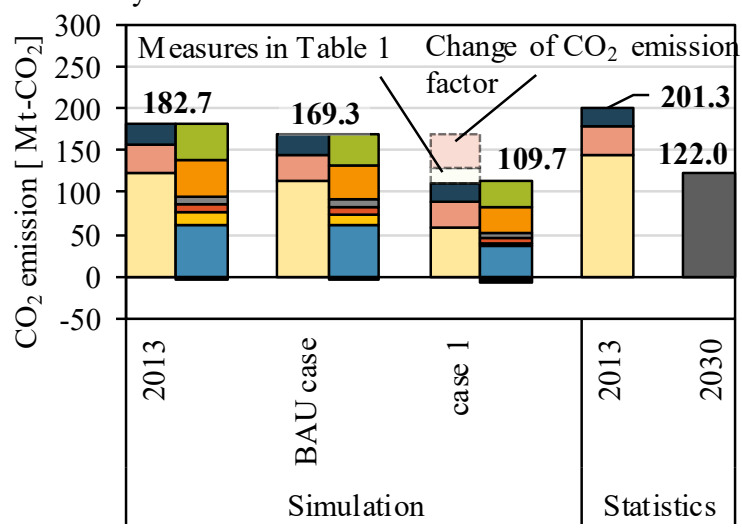

Figure 12: $\mathrm{CO}_{2}$ emissions in 2013 and 2030

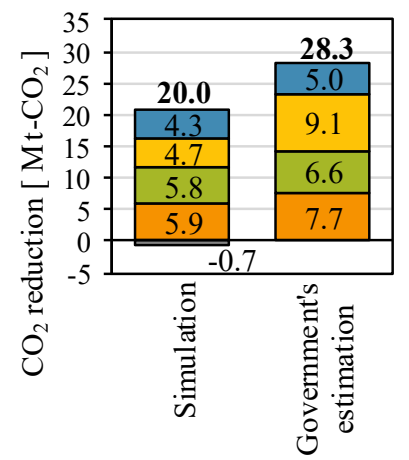

$\square$ Interaction between measures

$\square$ Improvement of appliance energy efficiency

$\square$ Installation of highefficiency lighting devices

$\square$ Installation of highefficiency water heaters

$\square$ Energy saving standard for housing insulation

Figure 13: $\mathrm{CO}_{2}$ emissions reduction from $\mathrm{BAU}$ case to case 1 
This gap of the reduction by installation of LEDs is caused by the difference between the methods of this study and the government's estimation. The government estimates have the unrealistic assumption that all lighting devices in all households operate for 2,000 hr/yr. In contrast, our model uses a lighting operation schedule determined from the occupant behaviour, the required illumination for every activity, and external conditions.

These results imply that occupant behaviour is particularly important for estimation of energy-saving effects related to lighting. Figure 14 shows the behaviour schedule of two couples (A: male office worker and female office worker; B: male office worker and housewife) on a typical weekday created by the model. The great difference between the couples' behaviour schedules is the hours staying at home during the daytime. Based on these behaviour schedules, the lighting operation schedule shown in Figure 15 was determined. Figure 16 shows the average of daily lighting operation hours of two households. The operation hours in living room $\mathrm{A}$ is around 3 hours longer than that of room $\mathrm{B}$. In addition, the operation hours also differ by room. This model enables us to accurately estimate the appliance effects that are strongly associated with the occupant behaviour.

Figure 17 shows the $\mathrm{CO}_{2}$ reduction by installation of highefficiency water heaters for cases 1,2 , and 3 . In cases 2 and 3 , the reduction effects are $8.6 \mathrm{Mt}$ and $2.2 \mathrm{Mt}$, respectively. Therefore, the distribution of the highefficiency water heaters results in a difference of $6.4 \mathrm{Mt}$ in $\mathrm{CO}_{2}$ reduction at the national scale. This value corresponds to approximately $30 \%$ of the total reduction (20.0 Mt) and larger than the simulation results for the reduction of each individual measure shown in Figure 13. Because this model considers the diversity of households, the model can evaluate the national reduction effected by diverse reduction effects.

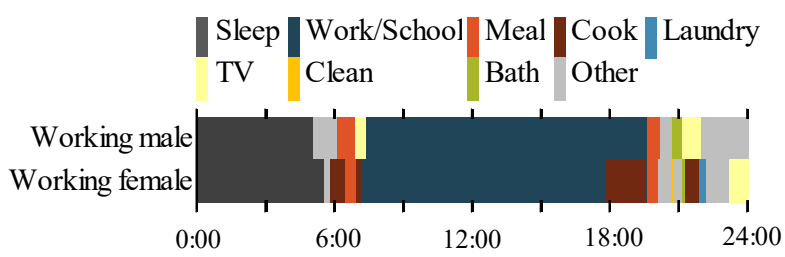

(a) Couple $A$

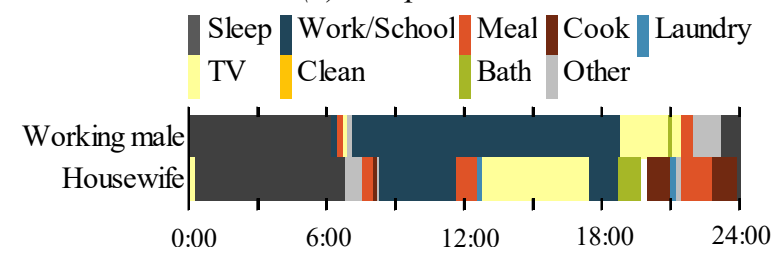

(b) Couple B

Figure 14: Occupant behaviour schedule of two couples

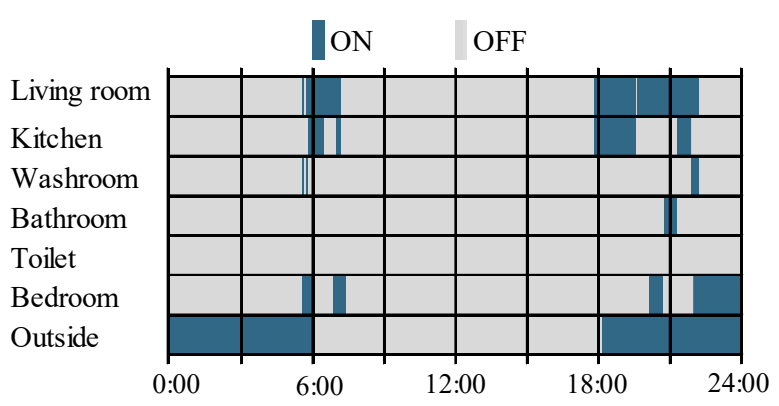

(a) Couple A

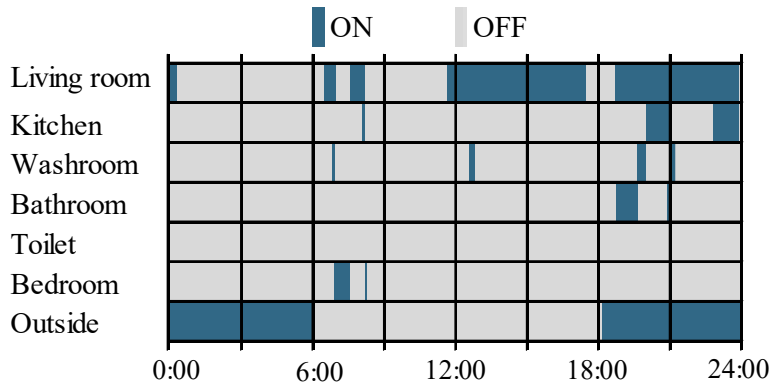

(b) Couple B

Figure 15: Lighting operation schedule of two couples

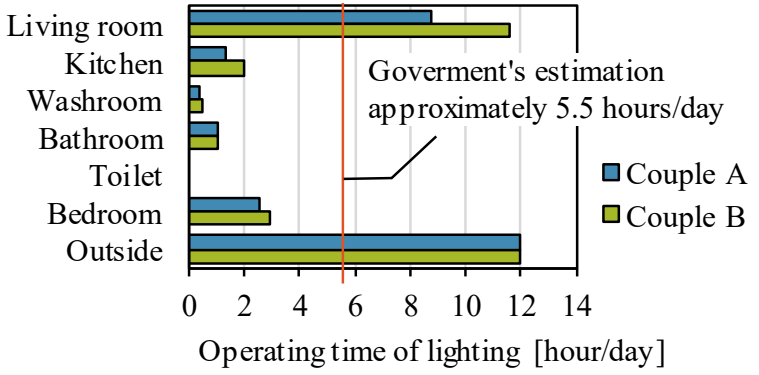

Figure 16: Annual average daily lighting operating hours

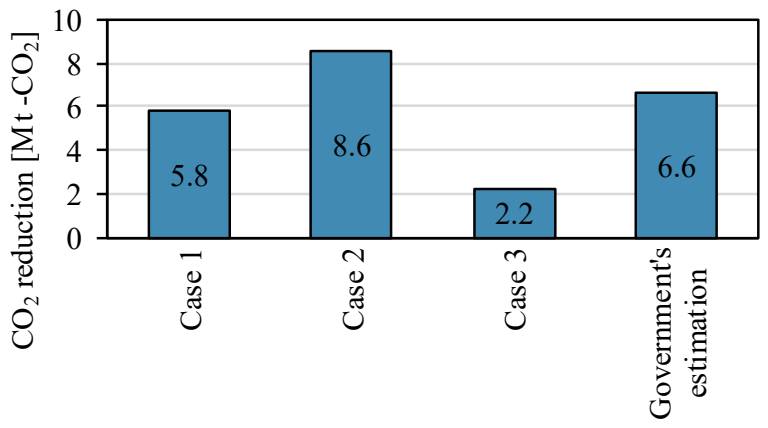

Figure 17: $\mathrm{CO}_{2}$ emissions reduction by installation of high-efficiency water heaters in each countermeasure case

\section{Discussion}

Household energy use has two characteristics. First, most energy use is driven by occupant behaviour. Second, it is affected by various household factors. As discussed in the introduction, the required specifications of a simulation model for global warming mitigation policy evaluation are driven by household behaviour and diversity. 


\section{Reproduction of the energy consumption habits in} actual households

The $\mathrm{CO}_{2}$ reduction effect by introduction of highefficiency appliances depends on the operation hours and occupant habits. For example, the operation status of lighting devices depends on the occupant presence and activity shown in Figure 14, 15, and 16. Therefore, models for policy making need to reproduce these habits to accurately estimate the effects of different habits. This point becomes increasingly important when sensing by a home energy management system becomes more common for evaluating occupant lifestyle changes.

\section{Consideration of household diversity}

The household energy consumption is affected by various factors, such as climate conditions, family composition, and building specifications. Therefore, $\mathrm{CO}_{2}$ reduction by introduction of various measures also differs by these factors. Therefore, for example, household $\mathrm{CO}_{2}$ reduction by introduction of high-efficiency water heaters differs by household category, as shown in Figure 10. It is predicted that the total amount of $\mathrm{CO}_{2}$ reduction by introduction of high-efficiency water heaters at a national scale varies by the distribution of each type of water heater, as shown in Figure 17. It is necessary to consider household diversity to accurately estimate the effect of each measure when planning global warming mitigation measures.

\section{Conclusion}

This paper discusses the required specifications of a bottom-up archetype simulation model to evaluate global warming mitigation policies. The required specifications are to reproduce the process of energy consumption in actual households and consider their diversity.

By using a model that satisfies these specifications, we estimated the $\mathrm{CO}_{2}$ emissions of the Japanese residential sector in 2013 and 2030. The model estimated a reduction of $\mathrm{CO}_{2}$ emissions from $182.7 \mathrm{Mt}$ in 2013 to $109.7 \mathrm{Mt}$ in 2030. This implies that if all energy-saving measures are realized and electricity $\mathrm{CO}_{2}$ emission factors are improved, the Japanese residential sector has the potential to achieve the $39 \%$ reduction target determined by the government. However, if each type of high-efficiency water heater is not distributed to the needed households, the effect of their installation will be much less than the assumed effects. This result was clarified by consideration of household diversity.

The simulated reduction by installation of LED lighting is approximately half of the government's estimate. The government produced estimates by assuming that all lighting in all households operates for 2,000 hr/yr. By contrast, we determined the operation state of lighting devices based on occupants' behaviour schedule. Because it is fundamentally driven by occupant behaviour, the method of this study can more realistically estimate the emissions reduction.

\section{References}

Agency for Natural Resources and Energy, Ministry of Economy (2015). Related Document to the Long-term Energy Supply and Demand Outlook, (in Japanese).

Agency for Natural Resources and Energy of METI. (2015). Comprehensive Energy Statistics in 2013.

Ministry of the Environment (2016). Cabinet Decision on the Plan for Global Warming Countermeasures.

Ministry of the Environment (2016). Test Statistic Survey on Nationwide Residential $\mathrm{CO}_{2}$ Emission.

Shimoda, Y., Asahi, T., Taniguchi, A., and Mizuno M. (2007). Evaluation of city-scale impact of residential energy conservation measures using the detailed enduse simulation model, Energy 32, 1617-1633.

Sweetnam, T., Spataru, C., and Barrett, M. (2017). The Socio-Economics and Energy Demand - United Kingdom Model (SEED-UK) Understanding the Dynamics, Diversity and Socio-Economics of the UK Domestic Stock. Proceedings from Building Simulation 2017. San Francisco (United States), 7-9 August 2017.

Sousa, G., Jones, B., Mirzaei, P. A. and Robinson, D. (2017) Platform for dynamic national housing stock simulation to evaluate decarbonization scenarios. Proceedings from Building Simulation 2017. San Francisco (United States), 7-9 August 2017.

Ballarini, I., Corgnati, S. P. and Corrado, V. (2014). Use of reference buildings to assess the energy saving potentials of the residential building stock: The experience of TABULA project. Energy Policy 68, 273-284.

Taniguchi, A., Shimoda, Y., Asahi, T., and Yamaguchi, Y. (2008). Modeling of Residential Energy End-Use Model for Japan and Evaluation on Effect of Improvement in Insulation. Journal of Environmental Engineering 73(632), 1217-1224. (in Japanese).

Wakiyama, T. and Kuramochi, T. (2017). Scenario analysis of energy saving and $\mathrm{CO} 2$ emissions reduction potentials to ratchet up Japanese mitigation target in 2030 in the residential sector. Energy Policy 103, 1-15.

Yamaguchi, Y. and Shimoda, Y. (2017). A stochastic model to predict occupants' activities at home for community-/urban-scale energy demand modelling. Journal of Building Performance Simulation 10(5-6), 565-581.

Fujii, T., Shimoda, Y., Morikawa, T. and Mizuno, M. (2005). Development of City Scale Residential Energy End-use Model Including Heat Load Calculation. Journal of Environmental Engineering 70(589), 51-58. (in Japanese). 